\title{
Oestrogen plus progestin was not effective for long term secondary prevention of coronary heart disease in postmenopausal women
}

hormone therapy: Heart and Estrogen/progestin Replacement Study follow-up (HERS II).JAMA 2002;288:49-57.

\section{QUESTION: In postmenopausal women with established coronary heart disease (CHD), does oestrogen plus progestin reduce the risks of $\mathrm{CHD}$ events after 6.8 years of follow up?}

\section{Design}

Randomised (allocation concealed*), placebo controlled trial. The study was blinded (patients, investigators, and outcome assessors)* for the initial mean 4.1 years of follow up and unblinded* for the subsequent mean 2.7 years of follow up (the latter 2.7 years was the HERS II study).

\section{Setting}

20 US outpatient and community centres.

Source of funding:

Wyeth-Ayerst Research.

For correspondence: Dr D Grady, University

of California at San

Francisco, San

Francisco CA, USA.

dgrady@itsa.ucsf.edu

Abstract and

commentary also

published in $A C P$

Journal Club

\section{Patients}

2763 postmenopausal women $<80$ years of age (mean age $67 \mathrm{y}$ ) with established CHD who had not had a hysterectomy. Of those alive at 4.1 years $(\mathrm{n}=2510)$, follow up was $84 \%$ at 6.8 years.

\section{Intervention}

Women were allocated to conjugated oestrogen, 0.625 $\mathrm{mg}$ /day, plus medroxyprogesterone acetate, $2.5 \mathrm{mg}$ /day $(n=1380)$, or placebo $(n=1383)$ for 4.1 years. In the subsequent 2.7 years (during HERS II), 1156 women in the oestrogen plus progestin group and 1165 women in the placebo group continued follow up, and open label hormone therapy was prescribed at the discretion of the women's personal physicians.

\section{Main outcome measures}

The main outcome was the composite end point of CHD death or nonfatal myocardial infarction (MI). Secondary outcomes included coronary artery bypass graft surgery, percutaneous coronary revascularisation, hospital admission for unstable angina or congestive heart failure, nonfatal ventricular arrhythmia, sudden death, stroke or transient ischaemic attack, and peripheral arterial disease.

\section{Main results}

Analysis was by intention to treat. The composite end point rate of CHD death or nonfatal MI did not differ between groups after mean follow up durations of 4.1 years, between 4.1 and 6.8 years, or at 6.8 years (table). Rates of CHD death, nonfatal MI, and secondary cardiovascular outcomes also did not differ between groups $(\mathrm{p} \geq 0.27)$.

\section{Conclusion}

In postmenopausal women with established coronary heart disease, oestrogen plus progestin did not reduce the risk of coronary heart disease events after 6.8 years of follow up.

*See glossary. 


\title{
Long term oestrogen plus progestin increased venous thromboembolism and biliary tract surgery in postmenopausal women
}

\author{
Hulley S, Furberg C, Barrett-Connor E, et al., for the HERS Research Group. Noncardiovascular disease outcomes during 6.8 \\ years of hormone therapy: Heart and Estrogen/Progestin Replacement Study follow-up (HERS II).JAMA. \\ 2002;288:58-66. \\ QUESTION: In postmenopausal women with established coronary heart disease (CHD), \\ what is the effect of oestrogen plus progestin on the risks of common non \\ cardiovascular disease outcomes after 6.8 years of follow up?
}

\section{Design}

Randomised (allocation concealed*), placebo controlled trial. The study was blinded (patients, investigators, and outcome assessors)* for the initial mean 4.1 years of follow up and unblinded* for the subsequent mean 2.7 years of follow up (the latter 2.7 years was the HERS II study).

\section{Setting}

20 US outpatient and community centres.

\section{Patients}

2763 postmenopausal women $<80$ years of age (mean age 67 y) with established CHD who had not had a hysterectomy. Exclusion criteria included deep venous thrombosis, pulmonary embolism, breast cancer, endometrial hyperplasia or cancer, abnormal Papanicolaou result, hormone use in the previous 3 months, and life threatening disease. Of those alive at 4.1 years, $(\mathrm{n}=2510)$, follow up was $84 \%$ at 6.8 years.

\section{Intervention}

Women were allocated to conjugated oestrogen, 0.625 $\mathrm{mg}$ /day, plus medroxyprogesterone acetate, $2.5 \mathrm{mg} /$ day $(n=1380)$, or placebo $(n=1383)$ for 4.1 years. In the subsequent 2.7 years (during HERS II), 1156 women in the oestrogen plus progestin group and 1165 women in the placebo group continued follow up, and open label hormone therapy was prescribed at the discretion of the women's personal physicians.

\section{Main outcome measures}

Venous thromboembolism, biliary tract surgery, cancer, fractures, and mortality.
Main results

Analysis was by intention to treat. At 6.8 years, women who received oestrogen plus progestin had increased risks of venous thromboembolism and biliary tract surgery (table). Rates of cancer, fractures, and total mortality did not differ between groups (table).

\section{Conclusion}

In postmenopausal women with established coronary heart disease, treatment for 6.8 years with oestrogen plus progestin increased the risks of venous thromboembolism and biliary tract surgery.

*See glossary.

Source of funding: Wyeth-Ayerst Research

For correspondence: Dr S Hulley, University of California at San Francisco, San Francisco, CA, USA shulley@epi.ucsf.edu

Abstract and commentary also published in ACP Journal Club

Effects of oestrogen plus progestin (Oest + Prog) v placebo on non-cardiovascular disease outcomes in postmenopausal women with coronary heart disease at 6.8 yearst

\begin{tabular}{|c|c|c|c|c|}
\hline \multirow[b]{2}{*}{ Outcomes } & \multicolumn{2}{|c|}{ Events/1000 person y } & \multirow{2}{*}{$\begin{array}{l}\text { Adjusted relative } \\
\text { hazard }(95 \% \mathrm{Cl}) \ddagger\end{array}$} & \multirow[b]{2}{*}{ NNH (Cl) } \\
\hline & Oest + Prog & Placebo & & \\
\hline $\begin{array}{l}\text { Venous } \\
\text { thromboembolism }\end{array}$ & 5.9 & 2.8 & 2.06 (1.26 to 3.36$)$ & 65 (35 to 187 ) \\
\hline Biliary tract surgery & 19.1 & 12.9 & $1.44(1.10$ to 1.90$)$ & 32 (19 to 107$)$ \\
\hline Any cancer & 19.7 & 16.5 & 1.19 (0.95 to 1.50$)$ & Not significant \\
\hline Any fracture & 29.7 & 28.4 & 1.07 (0.89 to 1.29$)$ & Not significant \\
\hline Total mortality & 30.6 & 27.8 & $1.08(0.91$ to 1.29$)$ & Not significant \\
\hline
\end{tabular}

†Abbreviations defined in glossary; $\mathrm{NNH}$ and $\mathrm{Cl}$ provided by author.

†Relative hazard calculated using a Cox proportional hazards model with intention to treat analyses and adjusted or some demographic and baseline characteristics.

\section{COMMENTARY—continued from previous page}

A reasonable consensus is now emerging. ${ }^{4-5}$ Firstly, HRT should not be prescribed to prevent CHD or used for general "prevention" purposes. Secondly, other alternatives for osteoporosis prevention should be considered and clinicians should be cautious about using HRT for the sole purpose of osteoporosis prevention. Finally, women should be advised of the risks and benefits before taking HRT to relieve menopausal symptoms. Although women may decide that the risks are worth relief of troublesome symptoms, they should use the lowest effective dose for the shortest time possible.

David Atkins, MD, MPH Agency for Healthcare Research and Quality Rockville, Maryland, USA

1 Hulley S, Grady D, Bush T, et al. Randomized trial of estrogen plus progestin for secondary prevention of coronary heart disease in postmenopausal women. Heart and Estrogen/progestin Replacement Study (HERS) Research Group. JAMA 1998:280:605-13.

Risks and benefits of estrogen plus progestin in healthy postmenopausal women: principal results from the Women's Health Initiative randomized controlled trial.

JAMA 2002;288:321-33.
The National Institutes of Health, The National Heart, Lung, and Blood Institute. Women's Health Initiative. www.nhlbi.nih.gov/whi/

4 U.S. Preventive Services Task Force. Postmenopausal hormone replacement therapy for primary prevention of chronic conditions. October 2002. www.preventives-

ervices.ahrq.gov

The North American Menopause Society Advisory Panel on Postmenopausal Hormone Therapy. October 2002. www.menopause.org 